\title{
Mechanical Behavior of Jute Hybrid Bio-Composites
}

\author{
Shane Johnson ${ }^{1,2}$, Liping Kang ${ }^{2}$, Hazizan Md Akil ${ }^{3}$ \\ ${ }^{1}$ State Key Laboratory of Mechanical System and Vibration, Shanghai Jiao Tong University, \\ Shanghai, China \\ ${ }^{2}$ University of Michigan and Shanghai Jiao Tong University Joint Institute, Shanghai Jiao Tong \\ University, Shanghai, China, shane.johnson@sjtu.edu.cn \\ ${ }^{3}$ School of Material and Mineral Resources Engineering, Universiti Sains Malaysia \\ Penang, Malaysia, hazizan@eng.usm.my
}

\begin{abstract}
Hybrid bio-composites are environmentally friendly and can provide a sustainable alternative to existing engineering materials in several applications. While these hybrid composites have relatively low modulus, their material consistency lend them to be used in many structural applications. Many low modulus natural fibers exhibit nonlinear axial stress strain relations.

Orthotropic material nonlinearity is typically analyzed for composites in the transverse and shear directions, and very few computational models consider axial nonlinearity. In this manuscript two new macro and one micromechanical constitutive models are developed to characterize the nonlinear orthotropic behavior of these material systems in the axial, transverse and shear directions. These models are then implemented within finite element (FE) code. A hybrid bio-composite in the form of pultruded layers manufactured with jute bio-fibers, combined with unidirectional roving E-glass, and embedded in a polymeric matrix was chosen for this study. Stress strain curves are generated for these dually reinforced systems in transverse, axial and shear modes to calibrate the nonlinear parameters for computational models. Photomicroscopy was also used to characterize the microsctructure to calibrate the micromechanical constitutive model. All three models are then validated under a multi-axial state of stress by full-field stress/strain analysis via Digital Image Correlation (DIC) and Thermoelastic Stress Analysis (TSA) of open-hole specimens. The results show that all of the models match the full-field TSA and DIC results under a multi-axial state of stress; however, the Anisotropic Potential Theory (APT) model based on the work of Hahn Tsai showed more response at stress concentrations than the Anisotropoic Deformation Theory (ADT) model based on the work of Hashin. Differences may have resulted from the correction scheme inplemented in the APT model. Also the Nine-Cell micromechanical model in this study based on the work of Haj-Ali et al was developed for comparison with the APT and ADT macromodels. The macromodels and micromodels presented here were implemented in ABAQUS user material subroutines, and are beneficial for analysis and design of structures with soft fiber constituents that have a nonlinear axial response.
\end{abstract}

Key words: A. Hybrid; C. Analytical modelling; C. Computational modelling; E. Pultrusion; Jute

\section{Introduction}

Hybrid fiber reinforced plastic (FRP) are composite material systems that can combine different forms of reinforcement layers, such as fibrous roving, continuous fillament mats (CFM), 
woven fabrics, and braided preforms. The reinforcement combination is usually repeated through the thickness of the cross-section of a flat member. Fibrous materials can be made of carbon, glass, aramid, natural fibers, yarns, fabrics etc. Matrix materials are commonly made of polyester or vinylester resin that includes additives such as glass microspheres and clay particles. Pultruded composites can include thin and thick-walled members (1/16 to 1 in.) having similar shapes to the standard steel beam shapes, such as wide-angle, channels, and angle sections. Recently, FRP pultruded composite materials have been widely applied for civil and infrastructural engineering applications, such as bridges, transmission towers, and structural components of buildings.

The demand for natural fiber composite systems is increasing, e.g., due to legislation for partially decomposable or compostable vehicles to reduce landfills. Many car manufacturers are using this "green" technology not only because it can be marketed as "green," but also because natural fiber systems can provide improved stiffness, weight, and insulation at lower cost than glass fibers [1]. In a review by Davies [2], materials engineers from various automotive manufacturers estimate that steel auto body weight may be reduced by $40-67 \%$ through the use of composite auto-bodies. In addition to car components in the automotive industry, natural fibers are also used for structural support in frames, decking materials, railings for parapet walls, furniture sections, wall panels, roofing sheets, temporary shelters, and post office boxes [3].

Natural fiber or bio-composites provide acceptable specific strength and modulus while offer several performance advantages over homogeneous Glass Fiber Reinforced Polymer (GFRP) composites including lower density, lower cost, bio degradability, and improved thermal/insulating properties $[4,5]$. One major disadvantage of natural fibers is the variability inherent in the material. Variability in mechanical properties in natural fibers is based on the harvesting season and region, local sun, rain and soil conditions, the part of the plant harvested, and the maturity of the plant $[6,7]$. Many sources list the longitudinal Young's Modulus of Jute Fibers from 20 - $40 \mathrm{GPa}$; which is 
significantly lower than the modulus of E-Glass fibers which have a longitudinal modulus of approximately $73 \mathrm{GPa}$. The discrepancies in the literature are possibly due to assumptions of a circular cross-section [8-12] in addition to the inherent mechanical variability of natural systems. Durability of natural fiber composites is a concern for any exposed application. Studies on natural fibers show that the severity of aging is most detrimental in accelerated water tests [13]. Also in some natural fiber systems fungal infestation can occur at cut edges of weathered composites. Failure of natural fiber composites due to delamination or fibre swelling in wet conditions has spurred further work into chemical treatments to increase moisture resistance in the fibres. Hybridizing can minimize the effect of natural fiber disadvantages, and several researchers showed that by hybridizing an optimum set of properties may be achieved. Ramesh et al. [14] found that sisal/jute/glass hybrids exhibited improved tensile strength and modulus compared with jute/glass or sisal/glass hybrids. Boopalan et al. [15] showed that a 50/50 jute/banana FRP exhibited higher tensile strength, flextural strength and impact strength over the single natural fiber composites. Sabeel Ahmed et al. [8] investigated various combinations of jute-glass laminates evaluating tensile, flexural, and interlaminar shear properties as measures of performance. The effect of hybridizing was investigated to minimize overall cost of the laminates taking advantage of the lower cost of jute while greatly increasing resistance to moisture absorption. They found that various jute/glass hybrids outperform homogenous glass or jute reinforced polymer systems when cost and moisture resistance is taken into account. Silva et al. [16] showed that sisal and jute fibers can replace glass and carbon fibers in many applications considering availability and cost.

Many experimental and analytical studies have been focused on the nonlinear response of laminated composite materials. Macrolevel theories are formulated to characterize the nonlinear response by idealizing the composite as an anisotropic homogeneous medium. Petit et al. [17] developed an orthotropic nonlinear algorithm for analyzing composite laminae. The tangent 
stiffness and strains of the laminate are updated at every stress increment by referring to empirical stress-strain relations of the previous increment, and so this method accumulates error especially with large load increments. Hahn and Tsai [18] developed a model for orthotropic composites that accounts for linear uni-axial behavior in axial and transverse directions but provides for nonlinearity in shear without coupling terms between the stress components. This nonlinear shear stress-strain relation is accomplished through an additional fourth-order term which is added to the complementary energy density polynomial function. Hahn [19] further developed this work to model the nonlinear behavior of composite laminates. Hashin et al. [20] developed a nonlinear model for unidirectional composite laminates by representing the transverse and shear stress-strain relations in the nonlinear Ramberg-Osgood form while the model of the axial fiber direction stress-strain relations is still linear. Jones and Nelson [21] developed a nonlinear material model where the material properties are related to the strain energy density by a nonlinear function similar in form to the Ramberg-Osgood relations. While initially intended to provide accurate results for multi-axial states when calibrated by uni-axial stress-strain empirical data, the extrapolation of the strain energy to multi-axial stress states was limited in application. Multi-axial modeling and predictions were later improved by Jones and Morgan [22] and Abu-Farsakh [22]. Amijima and Adachi [23] developed a method for accounting for nonlinear behavior of orthotropic composites in shear by dividing the shear stress-strain curve into several segments and representing the material by the piecewise linear relations for each segment. Sandhu [24] introduced an incremental approach similar to Petit et al.'s [17] technique for solution of the nonlinear laminate equations; however, a predictor-corrector iterative method is implemented with piecewise cubic spline functions to represent the lamina uniaxial test data and improve predictive accuracy. Nahas [25] presented a similar predictor-corrector technique to Sandhu [24], and the secant modulus is updated at each increment from empirically obtained and curve fitted uniaxial stress-strain relations from laminae. 
Kuppuswamy et al. [26] used the Richard and Abbott [27] representation for the modified Ramberg-Osgood relations to describe nonlinear orthotropic behavior of composites; however, the uniaxial stress-strain relations were uncoupled. Pindera and Herakovich [28] and Mathison et al. [29] derived a nonlinear plane stress constitutive model using orthotropic endochronic theory. The stress tensor at an instant of deformation, as formulated with endochronic theory, is a function of the parameter describing the history of deformation. Volumetric and shear mechanisms may be described using different parameters to describe nonlinearity and damage. Dvorak and Rao [30] proposed a plasticity theory for unidirectional composites where the microsctructure is assumed to consist of elastic fibers and an elastic-perfectly plastic matrix. A yield functions, hardening and flow rules were derived. Griffin [31] modified Hill's formulation for anisotropic plasticity using the Von Mises theory of plastic potential for the flow rule and isotropic hardening to model the nonlinear behavior of composites which would include plasticity and damage. Unidirectional Ramberg-Osgood relations were used to describe the nonlinear stress-strain relations of the material. Sun and Chen [32] developed a single parameter flow rule for an orthotropic plasticity model. Axial fiber direction plasticity is neglected; however, both transverse and shear stresses nonlinearities are described using the plastic potential.

Haj-Ali and Kilic [33] developed a multi-scale micromechanical model of orthotropic composites using linear and nonlinear constituents for the description of subcells in the repeating unit cell (RUC). Ramberg-Osgood relations are used to describe the matrix and linear relations to describe the fiber constituents. The homogenization provides for nonlinear behavior in the axial, transverse and shear directions. A predictive-corrective iterative approach is used to minimize error. The model is similar to Aboudi [34-36], and both are simplifications of the High Fidelity Generalized Method of Cells (HFGMC) model later developed by Haj-Ali et al.[37]. 
In previous studies, Haj-Ali Kilic [33] calibrated their multi-scale models through literature review and some limited experiments. The fiber volume fractions (FVFs), for example, of the unidirectional roving and the CFM were determined by a series of burn-out tests. Herakovich and Mirzadeh [38] studied the effects of the spatial distribution of fibers and fiber volume content on the effective properties of pultruded graphite/epoxy composites. Bank $[39,40]$ used the Iosipescu shear test to characterize in-plane shear modulus and strength of glass fiber pultruded specimens having vinylester and polyester matrix. The specimens were cut from the webs and angles of wide-angle pultruded beams. Pronounced nonlinear stress-strain relations were shown. Wang and Zureick [41] characterized the tensile behavior of coupon specimens cut from different locations of pultruded Ibeams. Flaws such as high void content and uneven distribution of reinforcement was significant in this material system. The specimen size effects on the effective properties were also examined. Tomblin and Barbero [42] performed analytical model to predict unidirectional compression strength of pultruded composites. Nonlinear responses were shown mainly due to fiber microbuckling. Nonlinear stress-strain behavior under multi-axial static loading can occur in pultruded FRP materials and structures. Haj-Ali and Kilic [43] conducted extensive off-axis tests, and they found that a pronounced nonlinear material response was evident in all directions of thick-section pultruded composites including the axial fiber direction. This material nonlinearity was attributed to the low fiber volume fraction (FVF) and behavior of the soft polymeric matrix.

Experimental studies have been performed to characterize the effective material properties and behavior of pultruded FRP composites with full-field remote sensing approaches. In this study the proposed models are validated with Thermoelastic Stress Analysis (TSA) and Digitial Image Correlation (DIC) for full-field analysis under a multi-axial state of stress. A more detailed description of techniques used for validation of computational analysis using TSA is available in the literature on static, fatigue, and fracture behavior of FRP composite materials for quantitative 
comparisons. Thomson [44] showed that temperature changes in isotropic linear elastic solids result from small deformations under adiabatic conditions according to the following relation:

$$
\Delta T=-\frac{T_{o} \alpha}{C_{p}} \sigma
$$

Eq. 1

where $\Delta T$ is the temperature change, $T_{o}$ is the ambient temperature, $\alpha$ the coefficient of thermal expansion, $C_{p}$ the heat capacity at constant pressure, and $\sigma_{\text {is }}$ the normal stress in the material. Biot [45] later expanded this formulation for anisotropic materials:

$$
\Delta T=-\frac{T_{o}}{C_{e}} \alpha_{k l} C_{i j k l} \varepsilon_{i j}
$$

Eq. 2

where $\alpha_{k l}$ is coefficients of thermal expansion in the principal directions, $C_{\varepsilon}$ is the volumetric specific heat at constant strain, $C_{i j k l}$ is the anisotropic material stiffness matrix, and $\varepsilon_{i j}$ is the strain in the material. These relations were later expanded to predict the behavior from the microstructure and simplify calibrations for model validations [46-48]. Johnson et al. developed TSA methods to characterize static damage in composite joints [49], fatigue damage in composite joints [50], and defects in bonding during manufacture of composites [51].

This study is aimed at investigating the linear and nonlinear mechanical behavior of Jute hybrid bio-composites. Section 2 of this manuscript introduces the macro models developed to analyze nonlinear behavior in composites. Two of these nonlinear anisotropic homogeneous models assume that the material is under a state of plane stress. The third is a nonlinear 3D micromechanical model using a cohesive micromechanical model, a special case (Nine-Cell) of the more general High Fidelity Generalized Method of Cells (HFGMC) proposed by Aboudi [52] and modified by Haj-Ali and Aboudi [37]. In Section 3, uni-axial tests are conducted to generate the stress-strain nonlinear response up to ultimate failure. Section 4 shows the results of full-field analysis of jute-glass hybrid composite under a multi-axial state of stress using TSA and Digital Image Correlation (DIC). Section 5 presents the discussion and results of this study. 


\section{Nonlinear Constitutive Models for Bio-composites}

Sections 2.1 and 2.2 of this manuscript describe the formulations for nonlinear orthotropic macromechanical models used for bio-composites. Section 2.3 of this manuscript describes the multiphase micromechanical constitutive model used for capturing nonlinear anisotropic behavior in bio-composites.

\subsection{Anisotropic Deformation Theory (ADT) Based Model}

The ADT model presented here is similar to Hashin's [20] anisotropic deformation theory with the addition of inelastic behavior for the $\sigma_{11}$ stress in the fiber direction.

Decomposing the strain into elastic and inelastic parts:

$$
\grave{\mathrm{o}}_{i j}=\grave{\mathrm{o}}_{i j}^{e}+\grave{\mathrm{o}}_{i j}^{I}
$$

Similar to the isotropic case: $\grave{\mathrm{o}}_{i j}^{I}=f\left(J_{2}\right) S_{i j}$, we assume:

$$
\begin{gathered}
\grave{\mathrm{o}}_{i j}^{I}=f(L) \sigma_{i j} \\
L=\alpha_{11}^{2} \sigma_{11}^{2}+\alpha_{22}^{2} \sigma_{22}^{2}+\alpha_{66}^{2} \sigma_{66}^{2}
\end{gathered}
$$

If the Ramberg-Osgood form is:

$$
\text { ò }=\frac{1}{E} \sigma+\frac{\beta \sigma_{o}}{E}\left(\frac{\sigma}{\sigma_{o}}\right)^{n}
$$

One dimensional Ramberg-Osgood relations in the 22 direction:

$$
\begin{gathered}
\grave{\mathrm{o}}_{22}=\frac{1}{E_{22}} \sigma_{22}+\beta_{2}\left(\frac{\left|\sigma_{2}\right|}{\sigma_{02}}\right)^{n_{2}-1} \sigma_{2} \\
\grave{\mathrm{o}}_{22}^{I}=\beta_{2}\left(\frac{\left|\sigma_{2}\right|}{\sigma_{02}}\right)^{n_{2}-1} \sigma_{22}=\beta_{2}\left[\left(\frac{\left|\sigma_{2}\right|}{\sigma_{02}}\right)^{2}\right]^{\frac{n_{2}-1}{2}} \sigma_{22}
\end{gathered}
$$

Taking the general form: $\grave{\mathrm{o}}_{22}^{I}=f_{22}(L) \sigma_{22}$, then:

$$
f_{22}(L)=f_{22}\left(\alpha_{22}^{2} \sigma_{22}^{2}\right)=\beta_{2}\left[\left(\frac{\left|\sigma_{2}\right|}{\sigma_{02}}\right)^{2}\right]^{\frac{n_{2}-1}{2}}
$$

And $\alpha$ can be defined as:

$$
\alpha_{11}^{2}=\sigma_{01}^{-2} ; f_{11}=\beta_{1} L^{\frac{n_{1}-1}{2}}
$$




$$
\begin{aligned}
& \alpha_{22}^{2}=\sigma_{02}^{-2} ; f_{22}=\beta_{2} L^{\frac{n_{2}-1}{2}} \\
& \alpha_{66}^{2}=\sigma_{06}^{-2} ; f_{66}=\beta_{6} L^{\frac{n_{6}-1}{2}}
\end{aligned}
$$

Therefore, the strains are defined in terms of the stresses as follows:

$$
\begin{gathered}
\grave{\mathrm{o}}_{11}=\frac{1}{E_{11}} \sigma_{11}-\frac{v_{12}}{E_{11}} \sigma_{22}+\beta_{1} L^{\frac{n_{1}-1}{2}} \sigma_{11} \\
\grave{\mathrm{o}}_{22}=-\frac{v_{12}}{E_{11}} \sigma_{11}+\frac{1}{E_{22}} \sigma_{22}+\beta_{2} L^{\frac{n_{1}-1}{2}} \sigma_{22} \\
\gamma_{12}=\frac{1}{G_{12}} \sigma_{12}+\beta_{6} L^{\frac{n_{6}-1}{2}} \sigma_{12}
\end{gathered}
$$

Then taking the derivatives of the strain relations with respect to the stress, we obtain:

$$
\begin{gathered}
\frac{\partial \grave{\mathrm{q}}_{1}}{\partial \sigma_{1}}=\frac{1}{E_{11}}+\frac{\beta_{1}}{E_{11}} L^{\frac{n_{1}-1}{2}}+\frac{\beta_{1}}{E_{11}}\left(\frac{n_{1}-1}{2}\right) L^{\frac{n_{1}-3}{2}} \frac{\partial L}{\partial \sigma_{11}} \sigma_{1} \\
\frac{\partial \grave{\mathrm{o}}_{11}}{\partial \sigma_{2}}=\frac{-v_{12}}{E_{11}}+\frac{\beta_{1}}{E_{11}} \frac{n_{1}-1}{2} L^{\frac{n_{1}-3}{2}} \frac{\partial L}{\partial \sigma_{22}} \sigma_{1} \\
\frac{\partial \grave{\mathrm{o}}_{11}}{\partial \sigma_{12}}=\frac{\beta_{1}}{E_{11}} \frac{n_{1}-1}{2} L^{\frac{n_{1}-3}{2}} \frac{\partial L}{\partial \sigma_{12}} \sigma_{1} \\
\frac{\partial L}{\partial \sigma_{11}}=\frac{2 \sigma_{11}}{\sigma_{01}^{2}} ; \frac{\partial L}{\partial \sigma_{22}}=\frac{2 \sigma_{22}}{\sigma_{02}^{2}} ; \frac{\partial L}{\partial \sigma_{12}}=\frac{2 \sigma_{12}}{\sigma_{06}^{2}}
\end{gathered}
$$

The tangent stiffness relations are therefore:

$$
\begin{gathered}
\frac{d \grave{\mathrm{o}}_{22}}{d \sigma_{11}}=\frac{-v_{12}}{E_{11}}+\frac{\beta_{2}}{E_{22}} \frac{n_{2}-1}{2} L^{\frac{n_{2}-3}{2}} \frac{\partial L}{\partial \sigma_{1}} \sigma_{2} \\
\frac{d \grave{\mathrm{o}}_{22}}{d \sigma_{22}}=\frac{1}{E_{22}}+\frac{\beta_{2}}{E_{22}} L^{\frac{n_{2}-1}{2}}+\frac{\beta_{2}}{E_{22}}\left(\frac{n_{2}-1}{2}\right) L^{\frac{n_{2}-3}{2}} \frac{\partial L}{\partial \sigma_{2}} \sigma_{2}
\end{gathered}
$$




$$
\begin{gathered}
\frac{d \grave{\mathrm{o}}_{22}}{d \sigma_{12}}=\frac{\beta_{2}}{E_{22}}\left(\frac{n_{2}-1}{2}\right) L^{\frac{n_{2}-3}{2}} \frac{\partial L}{\partial \sigma_{12}} \sigma_{2} \\
\frac{d \gamma_{12}}{d \sigma_{1}}=\frac{\beta_{6}}{G_{12}}\left(\frac{n_{6}-1}{2}\right) L^{\frac{n_{6}-3}{2}} \frac{\partial L}{\partial \sigma_{1}} \sigma_{6} \\
\frac{d \gamma_{12}}{d \sigma_{2}}=\frac{\beta_{6}}{G_{12}}\left(\frac{n_{6}-1}{2}\right) L^{\frac{n_{6}-3}{2}} \frac{\partial L}{\partial \sigma_{22}} \sigma_{6} \\
\frac{d \gamma_{12}}{d \sigma_{6}}=\frac{1}{G_{12}}+\frac{\beta_{6}}{G_{12}} L^{\frac{n_{6}-1}{2}}+\frac{\beta_{6}}{G_{12}}\left(\frac{n_{6}-1}{2}\right) L^{\frac{n_{6}-3}{2}} \frac{\partial L}{\partial \sigma_{12}} \sigma_{12}
\end{gathered}
$$

Eq. 23

\subsection{Anisotropic Potential Theory (APT) Model}

The APT model is an energy based nonlinear orthotropic model similar to Hahn-Tsai's [18] nonlinear orthotropic plane stress model with the addition of inelastic terms in the transverse and axial directions.

The energy function can be defined as:

$$
\mathbf{W}=\mathbf{W}\left(\sigma_{11}, \sigma_{22}, \sigma_{12}\right)=\mathbf{W}\left(\sigma_{1}, \sigma_{2}, \sigma_{6}\right)
$$

Eq. 26

The linear stress vs. strain relations take the form:

$$
\begin{gathered}
\grave{\mathrm{o}}_{11}=\frac{1}{E_{11}} \sigma_{11}-\frac{v_{12}}{E_{11}} \sigma_{22} \\
\grave{\mathrm{o}}_{22}=\frac{-v_{12}}{E_{22}} \sigma_{11}-\frac{1}{E_{22}} \sigma_{22} \\
\gamma_{12}=\frac{1}{G_{12}} \sigma_{12}
\end{gathered}
$$

The complementary energy function, $W^{\sigma}$, is the sum of the linear and nonlinear cases. W is the strain energy density.

$$
\mathbf{W}^{\sigma}=\mathbf{W}^{l}+\mathbf{W}^{n l}
$$

The linear case of the strain energy density is given by:

$$
\mathbf{W}^{l}=\frac{1}{2} \sigma_{i j} \grave{\mathrm{o}}_{i j}
$$

Expanding on the strain energy density from index format: 


$$
2 \mathbf{W}^{l}=\sigma_{11} \grave{\mathrm{o}}_{11}+\sigma_{22} \grave{\mathrm{o}}_{22}+2 \sigma_{12} \grave{\mathrm{q}}_{2}=\sigma_{11} \grave{\mathrm{q}}_{1}+\sigma_{22} \grave{\mathrm{o}}_{22}+\sigma_{12} \gamma_{12}
$$

Now substituting equations 25-27 for the linear strain energy density in equation 30, we obtain:

$$
2 \mathbf{W}^{l}=\frac{1}{E_{11}} \sigma_{11}{ }^{2}-\frac{2 v_{12}}{E_{11}} \sigma_{11} \sigma_{22}+\frac{1}{E_{22}} \sigma_{22}{ }^{2}+\frac{1}{G_{12}} \sigma_{12}^{2}
$$

The nonlinear case of the strain energy density is given by:

$$
2 \mathbf{W}_{\sigma}^{n l}=F_{1}\left(\sigma_{11}\right)+F_{2}\left(\sigma_{22}\right)+F_{6}\left(\sigma_{6}\right)
$$

To account for nonlinearity the 1D Ramberg-Osgood form is implemented in this model:

$$
\grave{\mathrm{o}}=\frac{1}{E} \sigma+\beta\left(\frac{|\sigma|}{\sigma_{o}}\right)^{\eta-1} \sigma
$$

Eq. 35

Taking the derivative with respect to the stress we obtain the one dimenstional stiffness in the Ramberg-Osgood form:

$$
\frac{\partial \grave{\mathrm{o}}}{\partial \sigma}=\frac{1}{E}+\beta \eta\left(\frac{|\sigma|}{\sigma_{o}}\right)^{\eta-1}
$$

The total strain is then the sum of the linear and non-linear parts is given by:

$$
\begin{gathered}
\grave{\mathrm{o}}_{11}=\frac{1}{E_{11}} \sigma_{11}-\frac{v_{12}}{E_{11}} \sigma_{22}+\beta_{1}\left(\frac{\left|\sigma_{11}\right|}{\sigma_{o 1}}\right)^{\eta_{1}-1} \sigma_{11} \\
\grave{\mathrm{o}}_{22}=-\frac{v_{12}}{E_{11}} \sigma_{11}+\frac{1}{E_{22}} \sigma_{22}+\beta_{2}\left(\frac{\left|\sigma_{22}\right|}{\sigma_{o 2}}\right)^{\eta_{2}-1} \sigma_{22} \\
\gamma_{12}=\frac{1}{G_{12}} \sigma_{12}+\beta_{6}\left(\frac{\left|\sigma_{12}\right|}{\sigma_{o 6}}\right)^{\eta_{6}-1} \sigma_{12}
\end{gathered}
$$

Iterative implementations of these relations are obtained within ABAQUS by solving for the stresses $\left(\sigma_{1}, \sigma_{2}, \sigma_{6}\right)$ given the strains $\left(\grave{\mathrm{o}}_{1}, \grave{\mathrm{o}}_{22}, \gamma_{12}\right)$ and the residual which is obtained by:

$$
\begin{aligned}
& \mathbf{R}_{1}=\frac{1}{E_{11}} \sigma_{11}-\frac{v_{12}}{E_{11}} \sigma_{22}+\beta_{1}\left(\frac{\left|\sigma_{11}\right|}{\sigma_{o 1}}\right)^{\eta_{1}-1} \sigma_{11}-\grave{\mathrm{q}}_{1}=0 \\
& \mathbf{R}_{2}=\frac{-v_{12}}{E_{11}} \sigma_{11}-\frac{1}{E_{22}} \sigma_{22}+\beta_{2}\left(\frac{\left|\sigma_{22}\right|}{\sigma_{o 2}}\right)^{\eta_{2}-1} \sigma_{22}-\grave{\mathrm{o}}_{22}=0
\end{aligned}
$$




$$
\mathbf{R}_{3}=\frac{1}{G_{12}} \sigma_{12}+\beta_{6}\left(\frac{\left|\sigma_{12}\right|}{\sigma_{o 6}}\right)^{\eta_{6}-1} \sigma_{12}-\gamma_{12}=0
$$

The tangent stiffness is given by:

$$
C_{T} \equiv\left[\frac{\partial R}{\partial \sigma}\right]^{-1}=\left[\begin{array}{ccc}
\frac{1}{E_{11}}+\beta_{1} \eta_{1}\left(\frac{\left|\sigma_{11}\right|}{\sigma_{o 1}}\right)^{\eta_{1}-1} & \frac{-v_{12}}{E_{11}} & 0 \\
\frac{-v_{12}}{E_{11}} & \frac{1}{E_{22}}+\beta_{2} \eta_{2}\left(\frac{\left|\sigma_{22}\right|}{\sigma_{o 2}}\right)^{\eta_{2}-1} & 0 \\
0 & 0 & \frac{1}{G_{12}}+\beta_{6} \eta_{6}\left(\frac{\left|\sigma_{12}\right|}{\sigma_{o 6}}\right)^{\eta_{6}-1}
\end{array}\right]^{-1}
$$

Eq. 43

The residual is a function of the stresses:

$$
R(\sigma)=R\left(\sigma_{1}, \sigma_{2}, \sigma_{6}\right)=0
$$

Eq. 44

Using Taylor expansion, the change in the stress for every increment is related to the residual by:

$$
\begin{gathered}
\Delta \sigma \equiv\left(\sigma^{(i+1)}-\sigma^{(i)}\right)=-\left.\left[\frac{\partial R}{\partial \sigma}\right]^{-1}\right|_{\sigma^{(i)}}\left\{R\left(\sigma^{(i)}\right)\right\} \\
R(\sigma) \cong R\left(\sigma^{(i)}\right)+\left.\left[\frac{\partial R}{\partial \sigma}\right]\right|_{\sigma^{(i)}}\left(\sigma^{(i+1)}-\sigma^{(i)}\right)=0 \\
\Delta \sigma=-\left.C_{T}\right|_{\sigma^{(i)}} R\left(\sigma^{(i)}\right)
\end{gathered}
$$

In general, the strains are given by:

$$
\begin{gathered}
\grave{\mathrm{o}}_{11}=\left[\frac{1}{E_{11}}+f_{1}\left(\sigma_{11}\right)\right] \sigma_{11}-\left[\frac{v_{12}}{E_{11}}+f_{21}\left(\sigma_{22}\right)\right] \sigma_{22} \\
\grave{\mathrm{o}}_{22}=-\left[\frac{v_{12}}{E_{11}}+f_{12}\left(\sigma_{11}\right)\right] \sigma_{11}+\left[\frac{1}{E_{22}}+f_{2}\left(\sigma_{22}\right)\right] \sigma_{22}
\end{gathered}
$$




$$
\gamma_{12}=\left[\frac{1}{G_{12}}+f_{6}\left(\sigma_{6}\right)\right] \sigma_{6}
$$

Note that assuming $f_{12}=f_{21}=0$ implies no nonlinear Poisson's effects.

\subsection{Cohesive Micromechanical (Nine-Cell) Model}

A cohesive micromechanical model for unidirectional lamina shown in Figure 1 was developed to compare the nonlinear response of the jute/glass bio composite with the ADT and APT models. The Nine-Cell model here represents a periodical medium of an array of long unidirectional fibers with rectangular cross-sections. The UC is composed of nine subcells that are given properties of the jute fiber, glass chop strand mat, and matrix constituents.

This model is similar to the doubly periodic multiphase composite media fully described and reviewed by Aboudi [34-36], and is a simplified version of the more general case of the High Fidelity Generalized Method of Cells given by Haj-Ali [37]. The effective stresses and strains of the UC are determined by satisfying, in an average sense, the traction continuity and strain compatibility constraints between the subcells. The new derivations are carried out assuming the micromodel is subject to uniform average strain rate for each time step. Correction schemes are implemented to account for errors in tangent stiffness (at the beginning of the increment) and the resulting stress increment. 

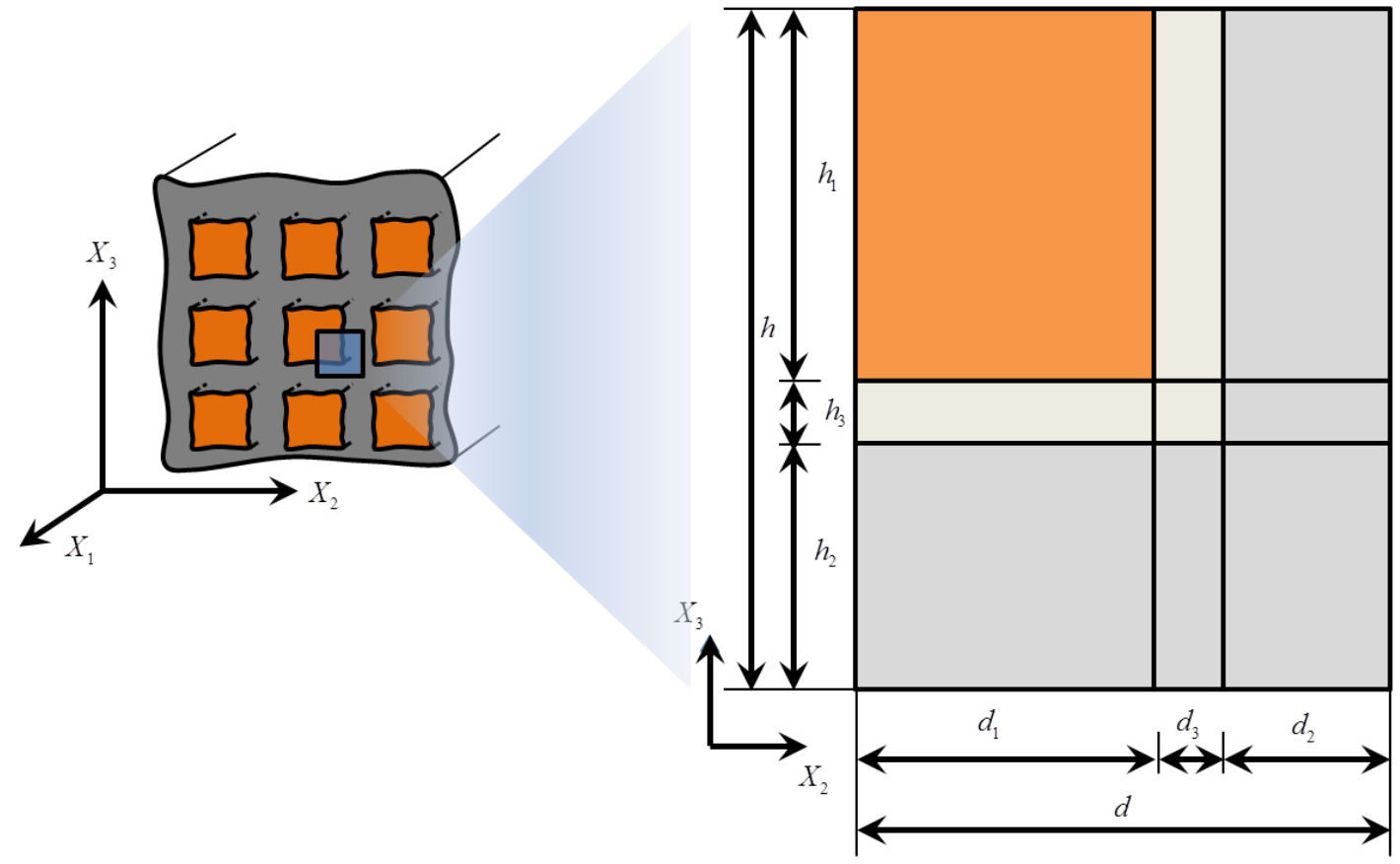

Figure 1: Idealized Medium with Periodic Arrays of Long Fibers (Rectangular Cross-Sections) Showing a Quarter UC (bold line), and the Nine-Cell Micromodel of Rectangular UC

\section{Calibration and Verification}

Section 3 presents experimental calibration and validation of the models implemented within ABAQUS [53] finite element program as formulated in Section 2.

\subsection{Jute Hybrid Bio-composite Systems}

The hybrid composite system for this study is composed of continuous jute yarns running the length of a flat pultruded plate sandwiched between glass chop strand mat surface layers. The glass mat reinforcement provides some transverse reinforcement. To get an estimate of the fiber volume fractions, photo microscopy was used to measure the cross-sectional areas of the jute fibers and chop strand glass mat layers. Notice in

Figure 2 that the jute fibers are a woven bundle-a non-circular shape. 
The jute fibers are visibly darker than the surrounding matrix and the chop strand mat glass layers, so this fact is used to apply image analysis algorithms to segment the fibers from the matrix. In

Figure 3, the first few steps are taken to create a binary image where segmented areas can be measured. The averaged properties of the material system obtained through photo microscopy are shown in Table 1.

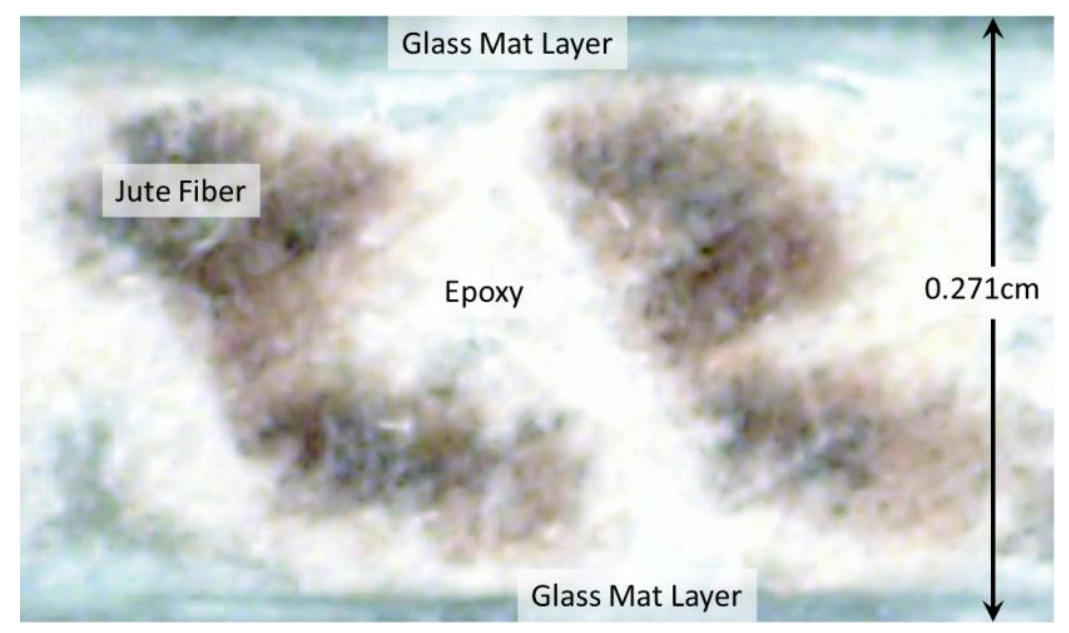

Figure 2: Hybrid Jute/Glass Composite with Chop Strand Mat Surface Layer

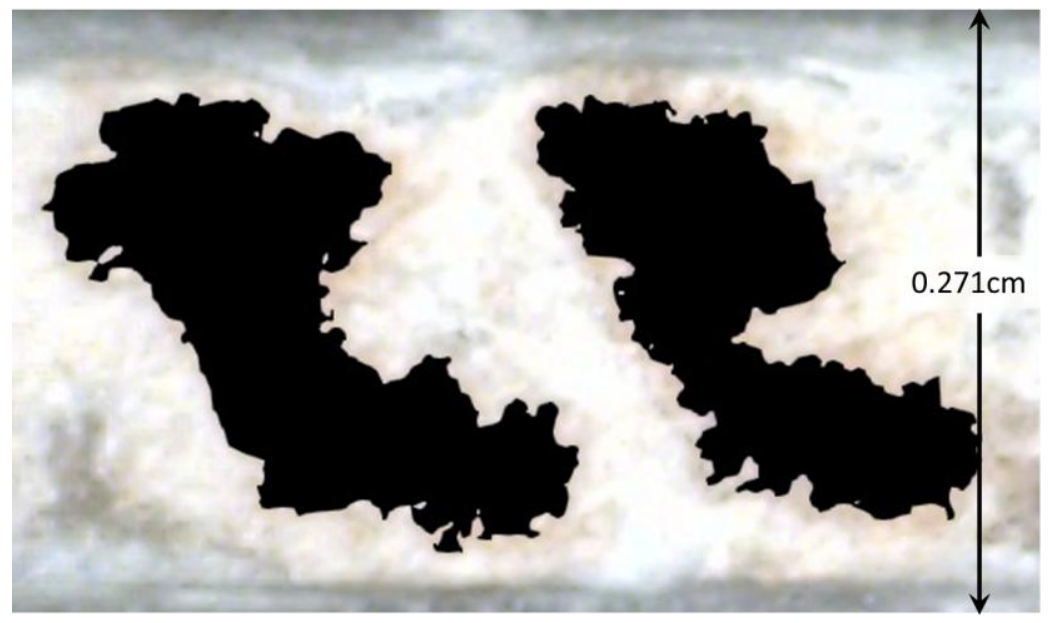

Figure 3: Color Similarity Algorithms used to Identify and Segment Jute Yarns from Background 


\section{Table 1: Description of Jute Hybrid Bio-composite Material System}

\begin{tabular}{|l|l|}
\hline Material Constituent & Volume Fraction \\
\hline Jute Yarn & 0.360 \\
\hline E-Glass Chop Strand Mat & 0.1325 \\
\hline Matrix & 0.5075 \\
\hline
\end{tabular}

Figure 4.A. shows the stress vs. strain relation for the jute/chop strand mat material system in tension in the fiber direction and compression in the transverse direction. The elastic modulus is taken between $1000-3000 \mu$.

Figure 4.B. shows the shear stress vs. shear strain relation for the jute/chop strand mat material system as tested in an Iosipescu test fixture. Table 9 in Appendix A shows the actual specimen dimensions which was later strain gauged as discussed in ASTM D5379. The ADT and APT models used the mean of the Ramberg-Osgood upper and lower bounds.

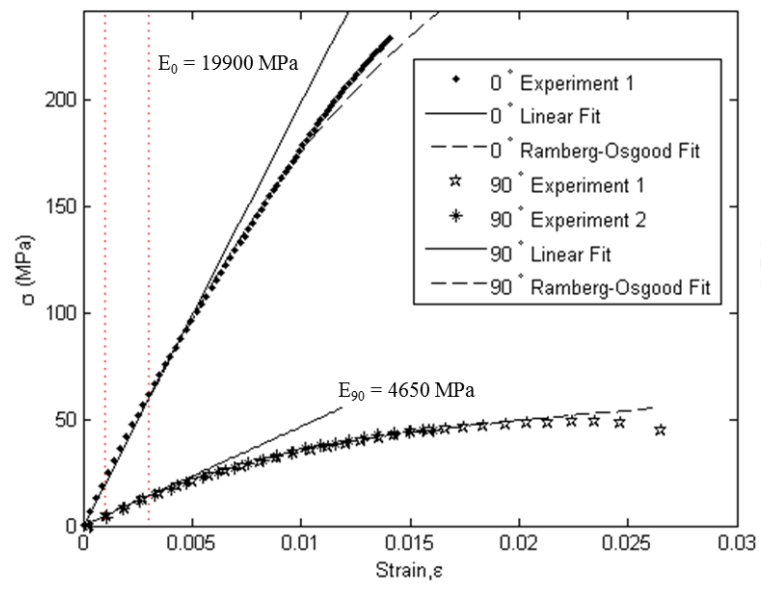

A.

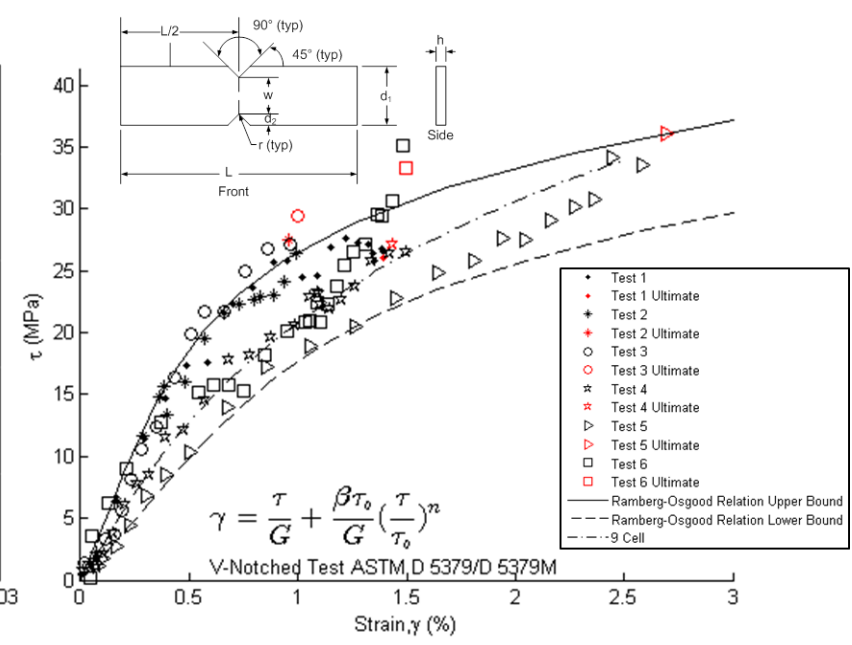

B.

Figure 4: (A.) Jute/Glass Chop Strand Mat System as Tested in Tension in the Fiber Firection, Compression in the Transverse Fiber Direction, and (B.) Shear with the Isopescu Shear Fixture 
The experimentally determined orthotropic elastic materials properties of the jute/glass chop strand mat system are shown in Table 2 .

Table 2: Unidirectional Elastic Material Properties of Jute with Chop Strand Mat

\begin{tabular}{|l|l|l|l|l|}
\hline$E_{11} \mathrm{MPa}(\mathrm{ksi})$ & $E_{22} \mathrm{MPa}(\mathrm{ksi})$ & $G_{12} \mathrm{MPa}(\mathrm{ksi})$ & $v_{12}$ & Thickness mm (in) \\
\hline $19890(2885)$ & $4650(675)$ & $3172(460)$ & 0.36 & $2.71(0.1065)$ \\
\hline
\end{tabular}

Fitting the experimental results to the Ramberg-Osgood relations $\mathrm{o}=\frac{\sigma}{E}+\frac{\beta \sigma_{0}}{E}\left(\frac{\sigma}{\sigma_{0}}\right)^{n}$ results in the calibrated Ramberg-Osgood relations and paramters for jute/glass chop strand mat are shown in Table 3.

Table 3: Calibrated Ramberg-Osgood Relations and Parameters for Jute / Glass Chop Strand Mat

\begin{tabular}{|l|l|l|l|l|}
\hline Direction & Modulus MPa (ksi) & $\sigma_{0}$ MPa (ksi) & $\beta$ & n \\
\hline 1 & $19890(2885)$ & $345(50)$. & 1 & 4.0 \\
\hline 2 & $4650(675)$ & $48(7)$. & 1 & 4.0 \\
\hline 6 & $4210(548)$ & $30 .(4.3)$ & 1 & 5.0 \\
\hline
\end{tabular}

The ultimate tensile stress in the axial direction and compressive stress in the transverse direction are given in Table 4. In addition, the translaminar fracture toughness was also calculated from experimental tests and provided in the table.

Table 4: Ultimate Material Properties of Jute with Chop Strand Mat

\begin{tabular}{|c|c|c|}
\hline$\sigma_{T 11} \mathrm{MPa}(\mathrm{ksi})$ & $\sigma_{C 22} \mathrm{MPa}(\mathrm{ksi})$ & $K_{T L} M P a \cdot m^{1 / 2}\left(k s i \cdot i n^{1 / 2}\right)$ \\
\hline $277(40.2)$ & $47.0(6.8)$ & $14.0(12.7)$ \\
\hline
\end{tabular}

Table 5 gives the linear orthotropic properties used for the Jute Yarn and E-Glass chop strand mat material constituents. Table 6 shows the nonlinear properties used to describe the matrix using Ramberg-Osgood relations. The linear and nonlinear shear properties for constitutents in the 
Nine-Cell model were modified from literature by fitting the overall model behavior to the experimental shear data as shown in

Figure 4.B.

Table 5: Nine-Cell RUC Linear Transversely Isotropic Material Properties

\begin{tabular}{|l|l|l|l|l|l|}
\hline Fiber & $E_{11} \mathrm{GPa}(\mathrm{ksi})$ & $E_{22} \mathrm{GPa}(\mathrm{ksi})$ & $v_{12}$ & $G_{12} \mathrm{GPa}(\mathrm{ksi})$ & $G_{23} \mathrm{GPa}(\mathrm{ksi})$ \\
\hline Jute Yarn & $46.9(6800)$ & $3.45(500)$ & 0.11 & $4.83(700)$ & $4.83(700)$ \\
\hline $\begin{array}{l}\text { E-glass Chop } \\
\text { Strand Mat }\end{array}$ & $6.89(1000)$ & $6.89(1000)$ & 0.25 & $5.52(800)$ & $5.52(800)$ \\
\hline
\end{tabular}

Table 6: Nine-Cell RUC Isotropic Nonlinear Matrix Material Properties (Ramberg-Osgood Relations)

\begin{tabular}{|l|l|l|l|l|l|}
\hline Material & $E_{11} \mathrm{GPa}(\mathrm{ksi})$ & $v_{12}$ & $\alpha$ & $S_{o} \mathrm{MPa}(\mathrm{ksi})$ & $\eta$ \\
\hline Matrix & $4.14(600)$ & 0.3 & 1 & $27.6(4)$ & 4 \\
\hline
\end{tabular}

Figure 5 shows a schematic representation of a Repeating Unit Cell (RUC) used here to show how the $\mathrm{X} l$ and $\mathrm{X} h$ parameters are used to describe the micromechanical geometry. Notice that the subcells are rectangular and six parameters are needed for the 3 by 3 geometry. Nine parameters are needed for the material identification of the subcells.

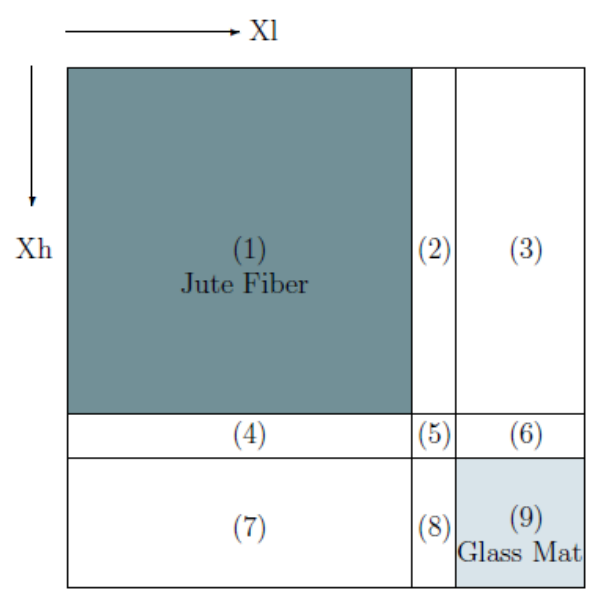

Figure 5: Nine-Cell RUC Geometry for System 1 
Various geometric combinations were chosen with equivalent volume fractions as shown in Table 7; however, very similar overall material properties were obtained as shown in Table 8.

Table 7: Nine-Cell RUC geometry for equivalent constituent volume fractions

\begin{tabular}{|l|l|l|l|l|l|l|l|}
\hline System & Geometry & $\mathrm{X} h 1$ & $\mathrm{X} h 2$ & $\mathrm{X} h 3$ & $\mathrm{X} l 1$ & $\mathrm{X} l 2$ & $\mathrm{X} l 3$ \\
\hline 1 & $(0,-0.2)$ & 1. & 0.06 & 0.6066758 & 1. & 0.06 & 0.6066758 \\
\hline 2 & $(0,-0.25)$ & 0.076369 & 1. & 0.076369 & 0.70486 & 1. & 0.70486 \\
\hline 3 & $(0,-0.3)$ & 0.173 & 1. & 0.173 & 0.53186 & 1. & 0.53186 \\
\hline 4 & $(0,-0.35)$ & 0.184028 & 1 & 0.184028 & 0.515228 & 1 & 0.515228 \\
\hline
\end{tabular}

Table 8: Nine-Cell RUC in-plane cell properties for equivalent volume fractions

\begin{tabular}{|l|l|l|l|l|l|}
\hline System & Geometry & $E_{11} \mathrm{MPa}(\mathrm{ksi})$ & $E_{22} \mathrm{MPa}(\mathrm{ksi})$ & $v_{12}$ & $G_{12} \mathrm{MPa}(\mathrm{ksi})$ \\
\hline 1 & $(0,-0.2)$ & $19950(2893)$ & $5390(782)$ & 0.27 & $2390(347)$ \\
\hline 2 & $(0,-0.25)$ & $19950(2893)$ & $5100(739)$ & 0.25 & $2520(366)$ \\
\hline 3 & $(0,-0.3)$ & $19930(2890)$ & $5150(747)$ & 0.25 & $2300(333)$ \\
\hline 4 & $(0,-0.35)$ & $19940(2892)$ & $4960(720)$ & 0.25 & $2540(369)$ \\
\hline
\end{tabular}

\section{Results and Validation}

Figure 6 shows the same open-hole specimen analyzed experimentally using TSA as shown in Figure 6.a and with Digital Image Correlation (DIC) as shown in

Figure 6.b. The TSA values are scaled by the remote axial stress and the DIC values are scaled by the axial modulus to simplify correlation with the proposed computational models. 


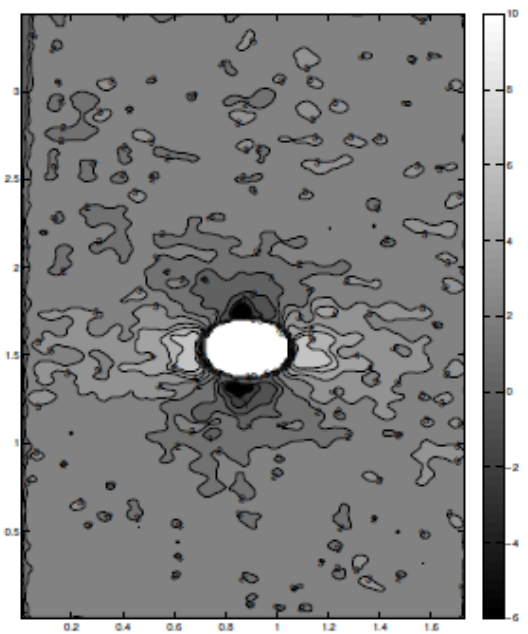

A. TSA

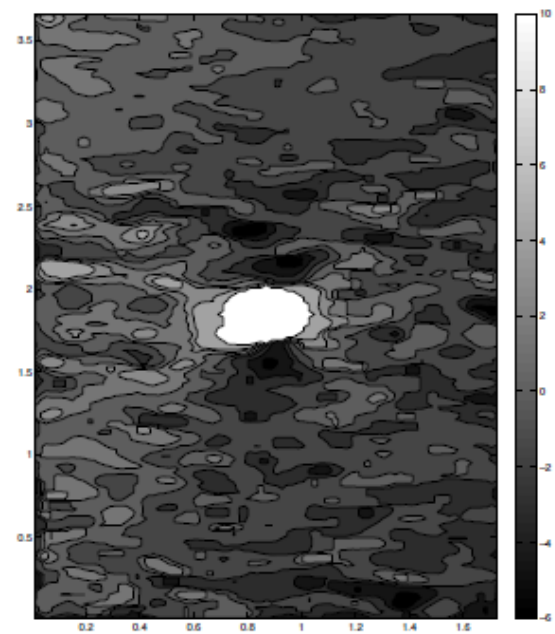

B. DIC

Figure 6: Contour map of (A.) TSA Image Scaled to Predicted Remote Axial Stress and (B.) Contour Map of Calculated Axial Stress from An Digital Image Coorelation (DIC) Method for An Open-hole Specimen (Specimen 1) of Jute with Chop Strand Mat Surface Layer

Figure 7 shows the contour plots of the axial stress for the two macromechanical nonlinear orthotropic computational models, a linear model, and the Nine-Cell models used in this study.

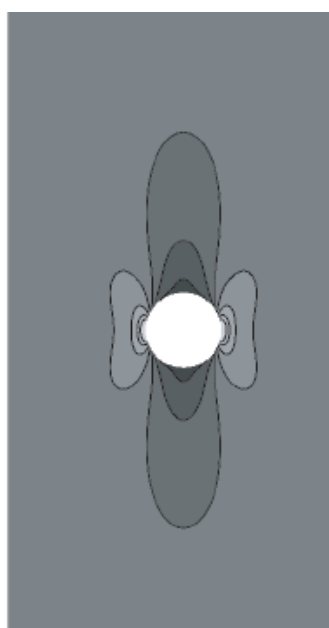

ADT

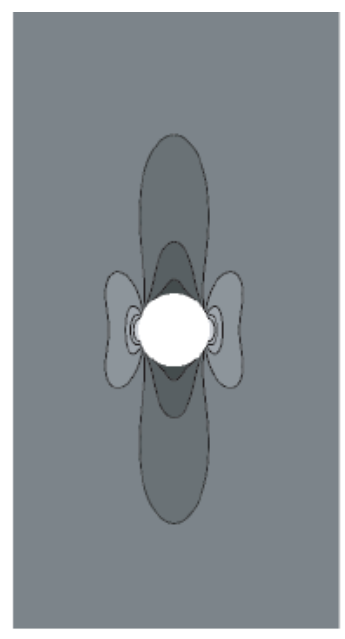

APT

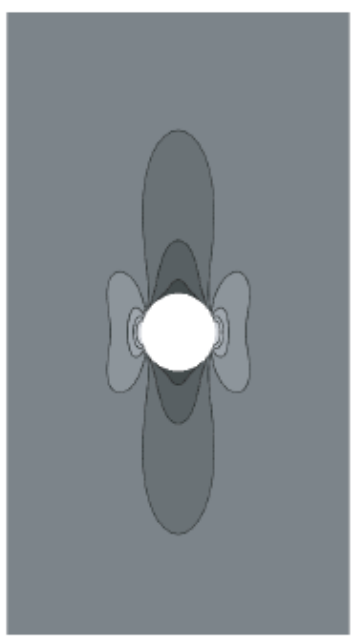

Linear

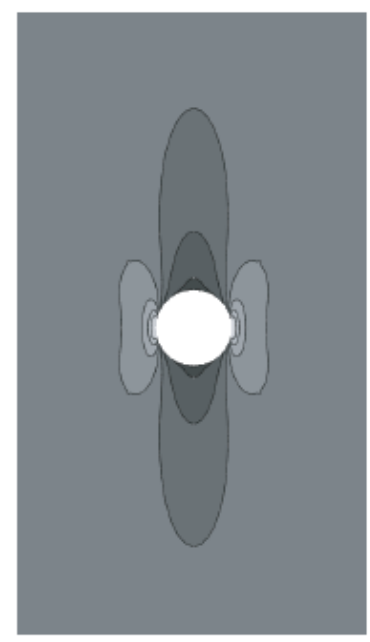

Nine-Cell

Figure 7: Contour Map of Predicted Remote Axial Stress of Open-hole Specimen Jute with Chop Strand Mat Surface Layer Showing ADT and APT Models

In addition to the qualitative analysis shown for the multi-axial state of stress modeled in

Figure 7, a line interrogation is shown in 
Figure 8 to show the prediction capabilities of the all of the proposed models.

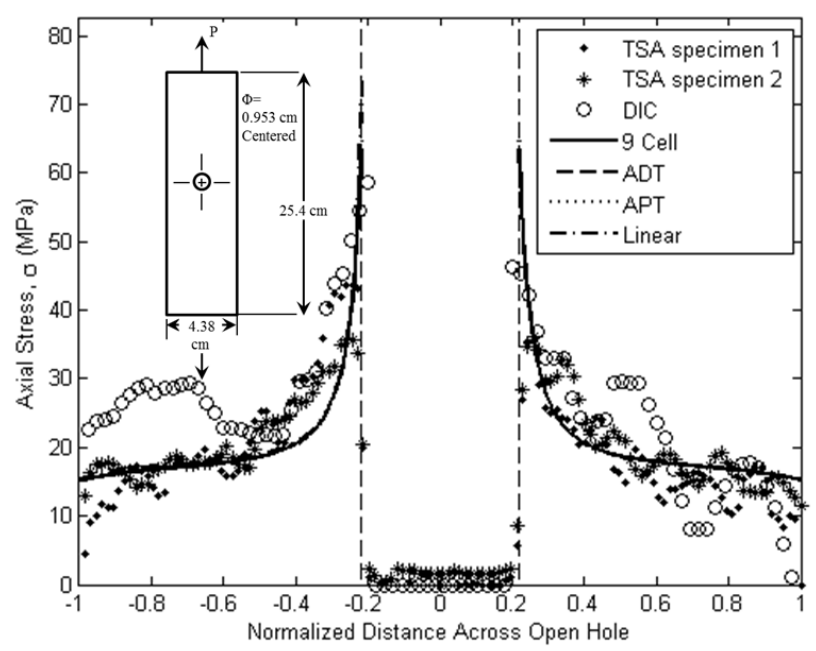

Figure 8: Axial Stress Line Interrogation on Open-Hole Specimen for 400lb Loading on Jute with Chop Strand Mat Material System Showing the Prediction Capabilities of the Nine-Cell, ADT, APT, and Linear Models

Figure 9 shows the remote axial stress vs. strain relation at location 1 (Centered horizontally and 1.63 inches above the open hole). The APT Model shows the greatest nonlinearity, but all of the models are close for the prediction of stress/strain response at location 1. Extended Finite Element Method (XFEM) was used in these models to predict failure based on fracture criterion.

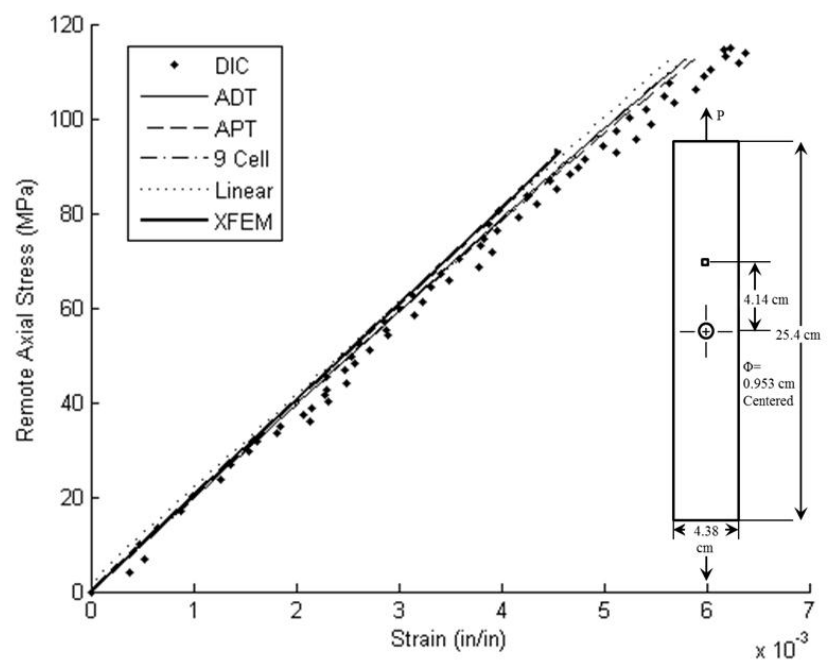

Figure 9: Remote Stress vs. Remote Axial Strain, DIC at Location 1 Used for Validation of the 


\section{ADT, APT, Nine-Cell Models, and Linear Orthotropic Models}

Figure 10 shows the remote axial stress vs. strain relation at location 2 (Centered vertically and at the edge of the open hole). Again the APT Model shows the greatest nonlinearity, followed by the ADT and Nine-Cell models. The linear model is shown here as a control for comparative purpose.

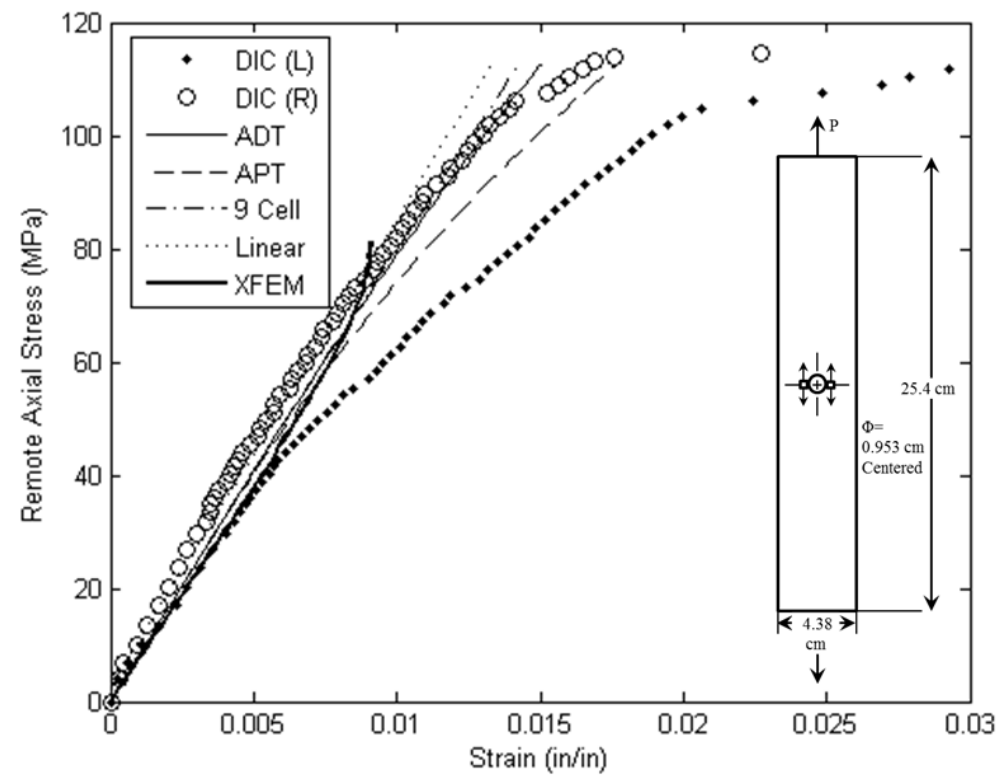

Figure 10: Remote Stress vs Axial Strain at Open Hole Edge, Image Correlation at Location 2 Used for Validation of the ADT, APT, Nine-Cell models, and Linear Orthotropic Models

Figure 11 shows the remote axial stress vs. strain relation at location 3 (Centered vertically and 0.625 inches from the center of the open hole). The ADT model shows the greatest nonlinear behavior followed by the APT and Nine-Cell models. 


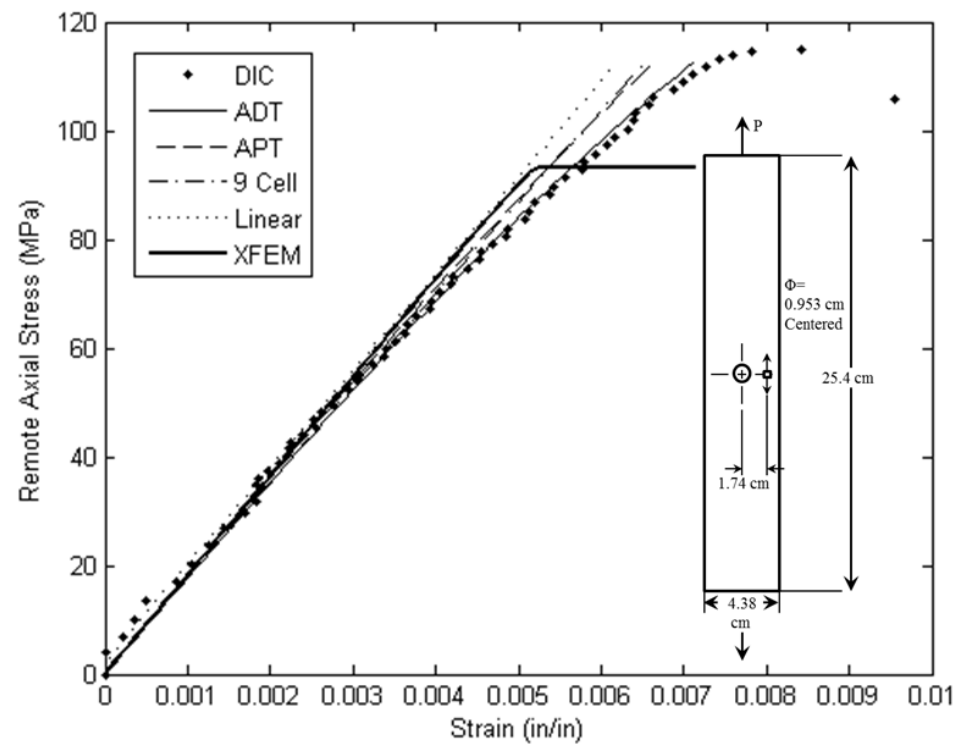

Figure 11: Remote Stress vs Axial Strain, Digital Image Correlation at Location 3 Used for Validation of the ADT, APT, Nine-Cell Models, and Linear Orthotropic Models

Figure 12 shows the remote axial stress vs. strain relation across the open hole $(3 / 4$ in gauge length extensometer). The ADT model shows the greatest nonlinear behavior followed by the APT and Nine-Cell models.

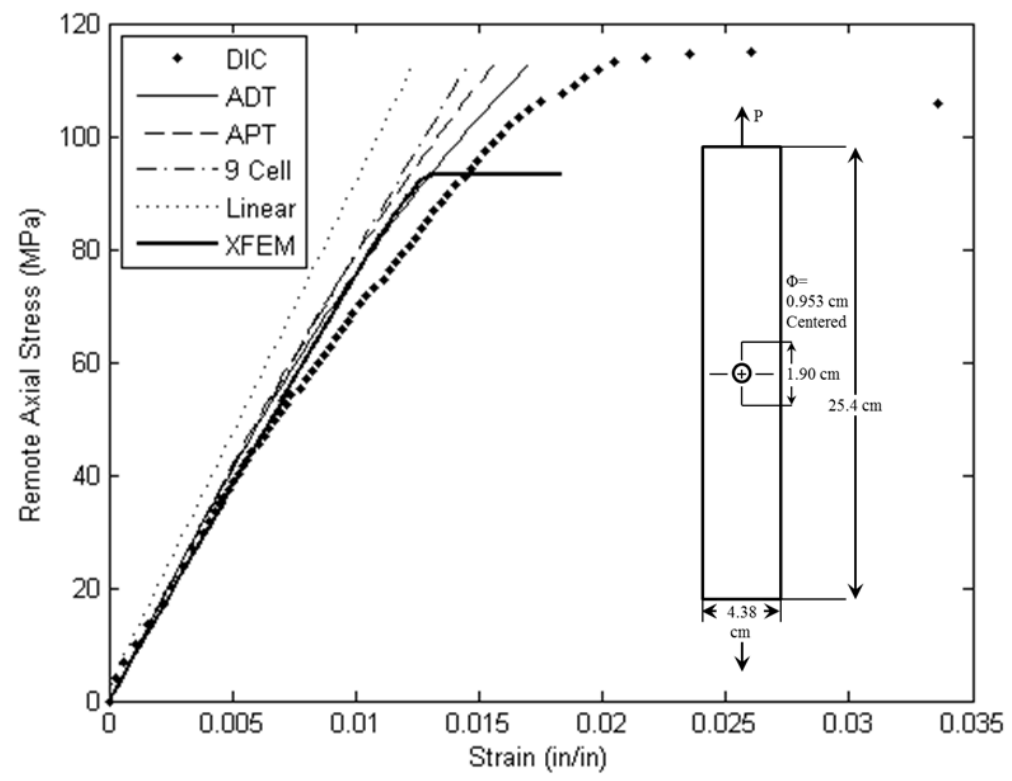

Figure 12: Remote Stress vs Axial Strain, Digital Strain Analysis Using 3/4 inch Gauge Length 


\section{Extensometer Over the Open Hole Used for Validation of the ADT, APT, Nine-Cell Models, and Linear Orthotropic Models}

\section{Discussion and Conclusions}

Two nonlinear orthotropic macro material models were developed in this study: (1) the Anisotropic Deformation Theory (ADT) model based on the work of Hashin [20], and (2) the Anisotropic Potential Theory (APT) model based on the work of Hahn-Tsai [18]. While axial and/or transverse nonlinearity was neglected in previous studies due to the selection of high modulus and strength fibers, this study considered axial, transverse, and shear nonlinearities in orthotropic composites due to the selection of low modulus and strength natural fibers. The APT model was also developed with correction algorithms to improve the accuracy for nonlinear simulations. In addition to the ADT and APT macromodels, a Nine-Cell micro model based on the work of Haj-Ali and Kilic [33] for modeling nonlinearity in pultruded composites was also developed for comparison. Damage was not considered in this study, but the Extended Finite Element Method (XFEM) was used to model the effect of nonlinearity in composites due to damage. All models were developed as ABAQUS user material (u-mat) subroutines.

The ADT and APT macromodels were calibrated with uni-axial experimental test results in the axial, transverse, and shear directions. These tests are typically carried out to characterize composite behavior. The Nine-Cell model required linear orthotropic values taken from the literature in the axial direction to describe the jute yarn, nonlinear isotropic values taken from the literature for the matrix, experimental stress vs. strain data in shear to calibrate the overall shear modulus, and estimates of the fiber and matrix volume fractions. Photomicroscopy tests and image segmentation were used in this study for estimates of fiber and matrix volume fractions as a fast alternative to burn-out tests performed by Haj-Ali and Kilic [33]. The Nine-Cell model can be implemented for different combinations or volume fractions of fiber/matrix constituents with limited set of experimental tests. 
The ADT, APT, Nine-Cell, and XFEM models proposed for comparison were able to capture the nonlinearity inherent in the material. These nonlinear orthoptropic models which were calibrated under a uni-axial state of stress are validated under a multi-axial state of stress by full-field stress/strain analysis via DIC and TSA of open-hole specimens. All models compared well with the experimental results. The ADT and APT models were able to capture more nonlinearity than the Nine-Cell model, and this may be due to the additional nonlinearity from the jute fiber constituent (modeled with a linear stress vs. strain relation in the Nine-Cell model). There is also a noticeable difference between the ADT and APT models under a multi-axial state of stress. The APT model showed a greater nonlinear effect from the stress concentration at the open hole than either the ADT or Nine-Cell models, and this is likely because of the iterative correction methodology implemented in the APT model.

The full-field experimental tests using TSA and DIC were helpful in validating the computational models under a multi-axial state of stress; however, only DIC was able to distinguish differences between the models. DIC captures the entire stress vs. strain relation full-field while TSA can only capture a change in temperature (a very small range of the stress vs. strain relation).

The ADT and APT macromodels and Nine-Cell micromodels presented here were implemented in ABAQUS with user material subroutines. This is beneficial for accurate analysis and design of structures with soft fiber constituents that have a nonlinear axial response.

\section{Acknowledgements}

This research was supported by State Key Laboratory of Mechanical System and Vibration at Shanghai Jiao Tong University and National Science Foundation of China funding under Grant No. 51550110233 and 51505282.

TSA data were collected on Georgia Tech Civil and Environmental Engineering equipment supervised by R. Haj-Ali, now of Tel Aviv University. 


\section{References}

[1] Bledzki A, Faruk O, Sperber V. Cars from Bio-Fibres. Macromolecular Materials and Engineering. 2006;291:449-57.

[2] Davies G. Materials for automobile bodies: Oxford: Replika Press Pvt. Ltd., 2003.

[3] Hong C, Hwang I, Kim N, Park D, Hwang B, Nah. Mechanical properties of silanized jute-polypropylene composites. Journal of Industrial and Engineering Chemistry. 2008;14 71-6

[4] Joshi SV, Drzal LT, Mohanty AK, Arora S. Are natural fiber composites environmentally superior to glass fiber reinforced composites? Composites Part a-Applied Science and Manufacturing. 2004;35:371-6.

[5] Jawaid M, Khalil H, Hassan A, Dungani R, Hadiyane A. Effect of jute fibre loading on tensile and dynamic mechanical properties of oil palm epoxy composites. Composites Part B-Engineering. 2013;45:619-24.

[6] Koronis G, Silva A, Fontul M. Green composites: A review of adequate materials for automotive applications. Composites Part B-Engineering. 2013;44:120-7.

[7] O'Donnell A, Dweib MA, Wool RP. Natural fiber composites with plant oil-based resin. Composites Science and Technology. 2004;64:1135-45.

[8] Ahmed KS, Vijayarangan S. Tensile, flexural and interlaminar shear properties of woven jute and jute-glass fabric reinforced polyester composites. Journal of Materials Processing Technology. 2008;207330 - 5 .

[9] Bisanda ETN, Ansell MP. J Mater Sci. 1992;27 1690-700.

[10] Roe PJ, Ansell MP. J Mater Sci. 1985;20 4015-20.

[11] Shan AN, Lakkard SC. Effect of interface modification on the mechanical properties of polystyrene-sisal fiber composites. Fibre Sci Technol. 1981;15 41-6

[12] Sridhar MK, Basavarajappa G. Indian J Text Res. 1982;79 87-92

[13] Singh B, Gupta M, Verma A. The durability of jute fibre-reinforced phenolic composites. Composites Science and Technology. 2000;60:581-9.

[14] Ramesh M, Palanikumar K, Reddy KH. Mechanical property evaluation of sisal-jute-glass fiber reinforced polyester composites. Composites Part B-Engineering. 2013;48:1-9.

[15] Boopalan M, Niranjanaa M, Umapathy MJ. Study on the mechanical properties and thermal properties of jute and banana fiber reinforced epoxy hybrid composites. Composites Part B-Engineering. 2013;51:54-7.

[16] Da Silva F, Filho RDT, Filho JdAM, Fairbairn EdMR. Physical and mechanical properties of durable sisal fiber-cement composites. Construction and Building Materials. 2010;24:777-85.

[17] Petit PH. A simplified method of determining the in-plane shear stress-strain response of unidirectional composites. ASTM STP 460. Philadelphia, PA; 1969. ASTM STP. 1969.

[18] Hahn TH, Tsai SW. Nonlinear elastic behavior of unidirectional composite laminae. J Compos Mater. 1973;7:102-18.

[19] Hahn TH. Nonlinear behaviour of laminated composites. J Compos Mater. 1973;7:257-71.

[20] Hashin Z, Bagchi D, Rosen BW. Nonlinear behavior of fiber composite laminates. NASACR-2313. 1974.

[21] Jones RM, Nelson Jr. DAR. A new material model for the nonlinear biaxial behavior of ATJ-S graphite. J Compos Mater. 1974;9:10-27.

[22] Jones RM, Morgan HS. Analysis of nonlinear stress-strain behavior of fiber reinforced materials. AIAA. 1977; 15:1669-76.

[23] Amijima SA, T. Nonlinear stress-strain response of laminated composites. J Compos Mater. 1979;13:206-18. 
[24] Sandhu RS. Non-linear behaviour of unidirectional and angle-ply laminates. J Aircraft. 1976;13:104-11.

[25] Nahas MN. Analysis of non-linear stress-strain response of laminated fibre-reinforced composites. Fibre Sci

Tech. 1984;20:297-313.

[26] Kuppuswamy T, Nada A, Reddy JN. Materially nonlinear analysis of laminated composite plates. Compos Struct. 1984;2:315-28.

[27] Richard R, Abbott B. Versatile elastic-plastic stress-strain formula. ASCE J Eng Mech Div, Technical Note. 1975;101:511-5.

[28] Pindera MJ, Herakovich CT. An endochronic model for the response of unidirectional composites under off-axis tensile load. IUTAM Symposium on Mechanics of Composite Materials. New York: Pergamon Press; 1983. p. 367-81.

[29] Mathison SR, Pindera MJ, Herakovich CT. Nonlinear response of resin matrix laminates using endochronic theory. J Eng Mat Tech. 1991;113:449-55.

[30] Dvorak GJ, Rao MS. Axisymmetric plasticity theory of fibrous composites. Int J Eng Sci. 1976;14:361-73.

[31] Griffin OH, Kamat MP, Herakovich CT. Threedimensional finite element analysis of laminated composites. J Composite Materials. 1981;5:543-60.

[32] Sun CT, Chen JL. A simple flow rule for characterizing nonlinear behavior of fiber composites. J Compos Mater. 1989.;23: 1009-20.

[33] Haj-Ali R, Kilic H. Nonlinear constitutive models for pultruded FRP composites. Mechanics of Materials. 2003;35 791 - 801

[34] Aboudi J. The generalized method of cells and high-fidelity generalized method of cells micromechanical models - a review. Mech Adv Materl Struct. 2004;11:329-66.

[35] Aboudi J. Micromechanical Analysis of Composites by the Method of Cells. Appl Mech Rev. 1989;42:193-221.

[36] Aboudi J. Mechanics of Composite Materials - A Unified Micromechanical Approach. Amsterdam, New York: Elsevier, 1991.

[37] Haj-Ali R, Aboudi J. Nonlinear micromechanical formulation of the high fidelity generalized method of cells. International Journal of Solids and Structures. 2009;46 2577 - 92

[38] Herakovich CT, Mirzadeh F. Properties of pultruded graphite/epoxy. J Reinforced Plastics Compos. 1991;10 2-28

[39] Bank LC. Shear properties of pultruded glass FRP materials. J Mater Civil Eng. 1990;2 118-22

[40] Bank LC, Yin J. Failure of web-angle junction in postbuckled pultruded I-beams. Journal of Composites for Construction. 1999:177-84

[41] Wang Y, Zureick A-H. Characterization of the longitudinal tensile behavior of pultruded I-shape structural members using coupon specimens. Composite Structures. 1994;29 463 - 72

[42] Tomblin J, Barbero EJ. Compression strength of pultruded fiber reinforced composites. Boulder, CO1995. p. 74-7

[43] Haj-Ali R, Kilic H. Nonlinear behavior of pultruded FRP composites. Composites Part B: Engineering. 2002;33 173 - 91

[44] Thomson W. On the thermoelastic, thermomagnetic and pyro-electric properties of matter. Phil Mag. 1878;5:4-27.

[45] Biot MA. Thermoelasticity and Irreversible Thermodynamics. Journal of Applied Physics. 1956;27:240-53.

[46] Wong AK, Jones R, Sparrow JG. Thermoelastic constant or thermoelastic parameter? J Phys Chem Solids. 1987;48:749-53.

[47] Emery TR, Dulieu-Barton JM, Earl JS, Cunningham PR. A generalised approach to the 
calibration of orthotropic materials for thermoelastic stress analysis. Compos Sci Techno. 2008;68:743-52

[48] Haj-Ali RM, El-Hajjar RF. A Thermoelastic Method for Strain Measurement in Coated Orthotropic Materials. Experimental Mechanics. 2004.

[49] Johnson S. Thermoelastic Stress Analysis for Detecting and Characterizing Static Damage Initiation in Composite Lap Shear Joints. Composites Part B: Engineering. 2014;56:740-8.

[50] Johnson S, Wei B, Haj-Ali R. A stochastic fatigue damage model for composite single lap shear joints based on Markov chains and thermoelastic stress analysis. Fatigue \& Fracture of Engineering Materials \& Structures. 2010;33:897-910.

[51] Johnson S, Popil R. Corrugated board bonding defect visualization and characterization. International Journal of Adhesion and Adhesives. 2015;59:105-14.

[52] Paley M, Aboudi J. Micromechanical analysis of composites by the generalized cells model. Mechanics of Materials. 1992;14:127 - 39

[53] ABAQUS Theory Manual. Providence, RI, USA: Dassault Systêmes Simulia Corp., 2007.

\section{Appendix A}

The specimen dimensions for the V-notch specimen used for shear testing are shown in Table 9.

Table 9: Nominal V-notch Specimen Dimensions

\begin{tabular}{|l|l|l|l|l|}
\hline $\mathrm{d} 1(\mathrm{~mm})$ & $\mathrm{d} 2(\mathrm{~mm})$ & $\mathrm{L}(\mathrm{mm})$ & $\mathrm{r}(\mathrm{mm})$ & $\mathrm{w}(\mathrm{mm})$ \\
\hline 20.0 & 4.0 & 76.0 & 1.3 & 12.0 \\
\hline
\end{tabular}

